\title{
Predictors of In-Hospital Events for Patients with Nonischemic Acute Heart Failure
}

\author{
Sudhkar Kanumuri ${ }^{1} \quad$ Neeharika Jonnalagadda ${ }^{2} \quad$ Indrani Garre ${ }^{1} \quad$ Maddury Jyotsna ${ }^{1}$ \\ ${ }^{1}$ Department of Cardiology, NIMS, Hyderabad, Telangana, India \\ 2Department of Nephrology, NIMS, Hyderabad, Telangana, India \\ Address for correspondence Sudhkar Kanumuri, DM, Department \\ of Cardiology, NIMS, Hyderabad, Telangana, India \\ (e-mail: sudhakarkanumuri87@gmail.com).
}

Ind J Car Dis Wom 2019;4:195-199

\begin{abstract}
Keywords

- acute coronary syndromes (ACS)

- nonischemic acute heart failure

- NT pro-BNP levels

- heart failure

Aim The main purpose of this article is to evaluate the clinical profile and in-hospital outcome among heart failure (HF) patients due to different diseases other than acute coronary syndromes (ACS) admitted in intensive coronary care unit (ICCU) at a tertiary center in South India.

Materials and Methods This is an observational study of HF patients who were admitted to ICCU for a period of 6 months from January 2019 to June 2019. ACS patients were excluded. All the demographic data, clinical history, examination details, electrocardiographic (ECG), two-dimensional echocardiography (ECHO), baseline routine, and special investigations were collected. In-hospital progress of the patient was monitored along with events (recurrence of HF, arrhythmias, acute kidney injury, cardiogenic shock, and death).

Results The total number of patients included in the study was 130 . The male:female ratio was 2.09:1(88/42) with a mean age of 53.61 years. Hypertension and diabetes were present in 52.3\% (68 patients). The etiology of HF was either ischemic (51 patients-39.2\%) or dilated (24 patients-18.4\%) cardiomyopathy in the majority of the patients (75 patients-57.6\%). Rest of the diagnosis for HF were hypertrophic cardiomyopathy in $6(4.6 \%)$ patients, chronic rheumatic heart disease in $18(13.8 \%)$ patients, primary pulmonary arterial hypertension in $6(4.6 \%)$ patients, severe valvular pulmonary restenosis in $3(2.3 \%)$ patients, Cor-pulmonale in $6(4.6 \%)$ patients, and others in 16 (12.3\%) patients. Events occurred in 17 patients (13.1\%). Mortality occurred in 6 patients (4.62\%). Patients with events had more severe dyspnea with pedal edema with low systolic blood pressure clinically; all patients had ECG abnormalities with more severe left ventricular (LV) dilatation with right and LV dysfunction with significant functional mitral regurgitation (MR) with more laboratory abnormalities including grossly elevated $\mathrm{N}$-terminal pro B-type natriuretic peptide (NT pro-BNP) levels when compared with patients without events. All the above said parameters were statistically significant $(p<0.05)$.

Conclusion The common cause of $\mathrm{HF}$ admissions in ICCU was predominantly due to ischemic cardiomyopathy. Still, valvular heart diseases were accounting for $13.8 \%$ of admissions. High incidence of event rate (13.1\%) despite the improvement in treatment strategies of ICCU patients in this new era, also the all-cause in-hospital mortality, was $4.62 \%$. There were multiple clinical (degree of dyspnea, pedal edema, low systolic blood pressure), ECHO (LV dilatation with dysfunction, right ventricle dysfunction, significant MR), and laboratory parameters (pre-azotemia, anemia, thrombocytopenia, grossly elevated NT pro-BNP levels) to predict the in-hospital events.
\end{abstract}

DOI https://doi.org/

$10.1055 / \mathrm{s}-0039-3402533$
C2019 Women in Cardiology and

Related Sciences
License terms

(1) (1) $\odot \circledast$ 


\section{Introduction}

There is increasing heart failure (HF) admissions to the intensive care unit (ICU) due to improving the management of acute coronary events leading to increasing survival but with the disabilities. ${ }^{1}$ The incidence of HF is increasing because of improved survival after myocardial infarction. There are studies on the predictors of mortality and morbidity in theses HF patients, ${ }^{2}$ and there is a significant improvement in the treatment strategies of HF, including sacubitril-valsartan therapy. Despite this, still, the mortality rate is increasing in patients with HF. We require further studies to know the determinants for the events in patients with HF for further management.

\section{Methods}

This observational study from a referral center in South India. The patients admitted to the intensive coronary care unit (ICCU) with HF without acute coronary syndromes (ACS) were included for this study. The study duration was from January 2019 to June 2019, that is, 6 months. Patients presented with ACS were excluded from the study. All the demographic data, including age, sex, address, clinical history, examination details, electrocardiographic (ECG), two-dimensional echocardiography (ECHO), baseline routine, and special investigations, were collected. Patients managed symptomatically and interventional procedures were done according to clinical diagnosis. Patients are daily monitored for clinical improvement. Outcome during present admission in terms of either recovery or mortality or any other events (recurrence of HF, arrhythmias [either atrial or ventricular], acute kidney injury, cardiogenic shock, and death) and duration of hospital stay was noted.

\section{Results}

During the period of the study, a total of $130 \mathrm{HF}$ patients, comprising 88 (67.6\%) males and 42 (32.4\%) females, were admitted into the ICCU. Their mean age of the study population was $53.61 \pm 13.06$ years. The associated comorbidities/ risk factors in the study group include diabetes in 68 (52.3\%), hypertension in 68 (52.3\%), smoking in 32 (27.6\%), and alcoholism in 39 (30\%) patients.

The distribution of diagnosis of cardiac conditions leading to HF necessitating admission into CCU was as follows: ischemic cardiomyopathy in 51 (39.2\%), dilated cardiomyopathy in 24 (18.4\%), hypertrophic obstructive cardiomyopathy in 6 (4.6\%), chronic rheumatic heart disease in 18 (13.8\%), primary pulmonary artery hypertension (PAH) in $6(4.6 \%)$, severe pulmonary restenosis ( $\mathrm{S} / \mathrm{P}$ percutaneous balloon pulmonary valvuloplasty) in 3 (2.3\%), Cor-pulmonale in 6 (4.6\%), and other causes in 16 patients (12.3\%).

The mean pulse rate was $90+8 \mathrm{bpm}$; Mean systolic blood pressure and mean diastolic blood pressure were $110+12.3$ and $68.4+7.9 \mathrm{~mm} \mathrm{Hg}$, respectively. Electrocardiographic findings were as follows: normal sinus rhythm was seen in 70 (53.8\%), sinus tachycardia in 34 (26.1\%), complete heart block in $6(4.6 \%)$, atrial fibrillation in $8(6.1 \%)$, atrial tachycardia in $3(2.3 \%)$, and ventricular tachycardia in $9(6.9 \%)$ patients. Two-dimensional ECHO helped in the primary diagnosis of the underlying cause for HF. Renal parameter abnormalities were seen in $35(26.9 \%)$ patients. Mean creatinine was $1.77 \pm$ $1.8 \mathrm{mg} \%$; abnormal liver functions were seen in 18 (13.8\%). Mean hemoglobin $(\mathrm{Hb})$ was $11.7 \pm 1.47 \mathrm{gm} \%$.

The average duration of hospital stay was $10.5 \pm 5.4$ days. All these patients were followed to see whether they developed any complications or improved/discharged or succumbed to death. We made two groups depending on whether the complication occurred or not. Seventeen patients had complications either singularly or in combination (-Fig. 1). The complications noted were a recurrence of HF (6 patients-in one patient precipitating cause for HF was ventricular tachycardia), acute kidney injury (5 patients), cardiogenic shock, and death (6 patients). Mortality was seen in $6(4.62 \%)$ patients.

Group 1 was patients without complications, and Group 2 was patients with complications. There was no difference in the complication rates between males and females. Group 2 patients had more diabetics $(p=0.046)$ and more severe dyspnea $(p=0.012)$ with pedal edema $(p=0.00)$ than Group 1 patients (-Table $\mathbf{1}$ ).

Clinically Group 2 patients had lower systolic $\mathrm{BP}(p=0.00)$, with ECG abnormality $(100 \%, p=0.00)$ with larger left ventricle (LV) $(p=0.00)$ with RV ( $p=0.004)$ and LV dysfunction $(p=0.00)$ with significant functional mitral regurgitation $(p=0.012)$ and pericardial effusion $(p=0.00)$ on ECHO than Group 1 patients, which were statistically significant

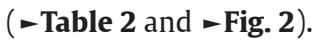

The Group 2 patients had more prerenal azotemia $(p=0.038)$ and less $\mathrm{Hb}(p=0.005)$ with thrombocytopenia $(p=0.00)$ along with higher $\mathrm{N}$-terminal pro B-type natriuretic peptide (NT pro-BNP) levels $(p=0.00)$ than Group 1 patients,

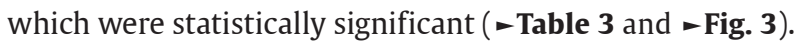

All the patients who died were from the ischemic cardiomyopathy group. Other patients were stabilized and discharged. Some valvular patients (mitral stenosis and pulmonary stenosis) even undergone therapeutic procedures before discharge.

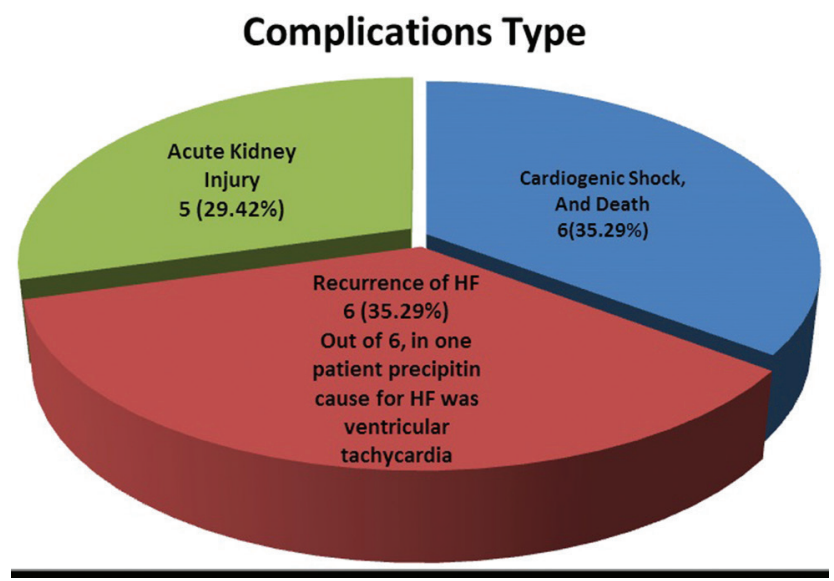

Fig. 1 In-hospital events in the study population. 
Table 1 Comparison of demographic, clinical, and risk factors in both groups

\begin{tabular}{|l|l|l|l|}
\hline Parameters & Group 1 (without complications) & Group 2 (with complications) & -Value \\
\hline No & 113 & 17 & \\
\hline Age (years) & $53.8 \pm 13.7$ & $52.3 \pm 10.1$ & 0.55 \\
\hline Sex (male) & $76(67.3 \%)$ & $12(70.58 \%)$ & 0.780 \\
\hline Hypertension (\%) & $51(45.1 \%)$ & $11(64.7 \%)$ & 0.117 \\
\hline Diabetes mellitus (\%) & $45(39.8 \%)$ & $11(64.7 \%)$ & 0.046 \\
\hline SM (\%) & $16(14.15 \%)$ & 0 & - \\
\hline Alcoholic (\%) & $22(19.46 \%)$ & $4(23.52 \%)$ & 0.711 \\
\hline Shortness of breath (\%) & $107(94.69 \%)$ & $17(100 \%)$ & 0.012 \\
\hline Palpitations (\%) & $29(25.66 \%)$ & $5(29.41 \%)$ & 0.751 \\
\hline Swelling of feet (\%) & $47(41.59 \%)$ & $17(100 \%)$ & 0.000 \\
\hline Absevi & \\
\hline
\end{tabular}

Abbreviation: SM, smoking.

Table 2 Comparison of demographic, clinical, and risk factors in both groups

\begin{tabular}{|l|l|l|l|}
\hline Parameters & Group 1 (without complications) & Group 2 (with complications) & p-Value \\
\hline No & 113 & 17 & 0.55 \\
\hline Age (year) & $53.8 \pm 13.7$ & $52.3 \pm 10.1$ & 0.073 \\
\hline Pulse (beats/min) & $95.0 \pm 22.4$ & $100.94 \pm 9.98$ & 0.000 \\
\hline Systolic blood pressure (mm Hg) & $118.0 \pm 21.5$ & $99.8 \pm 14.3$ & 0.000 \\
\hline Diastolic blood pressure (mm Hg) & $74.3 \pm 12.7$ & $66.47 \pm 4.93$ & 0.039 \\
\hline Left artery size (cm) & $4.171 \pm 0.53$ & $4.065 \pm 0.049$ & 0.000 \\
\hline Left ventricular dysfunction (cm) & $5.35 \pm 0.911$ & $5.941 \pm 0.197$ & 0.000 \\
\hline Left ventricular systolic function (cm) & $4.13 \pm 1.14$ & $5.176 \pm 0.246$ & 0.664 \\
\hline Conduction abnormality present (\%) & $67(59.3 \%)$ & $11(64.7 \%)$ & $17(100 \%)$ \\
\hline Left ventricular dysfunction present (\%) & $81(71.7 \%)$ & $12(70.6 \%)$ & 0.000 \\
\hline Right ventricle function yes (\%) & $41(36.3 . \%)$ & $17(100 \%)$ & 0.004 \\
\hline Mitral regurgitation (\%) & $107(94.6 \%)$ & $11(64.7 \%)$ & 0.012 \\
\hline Pericardial effusion (\%) & $24(21.2 \%)$ & & 0.000 \\
\hline
\end{tabular}

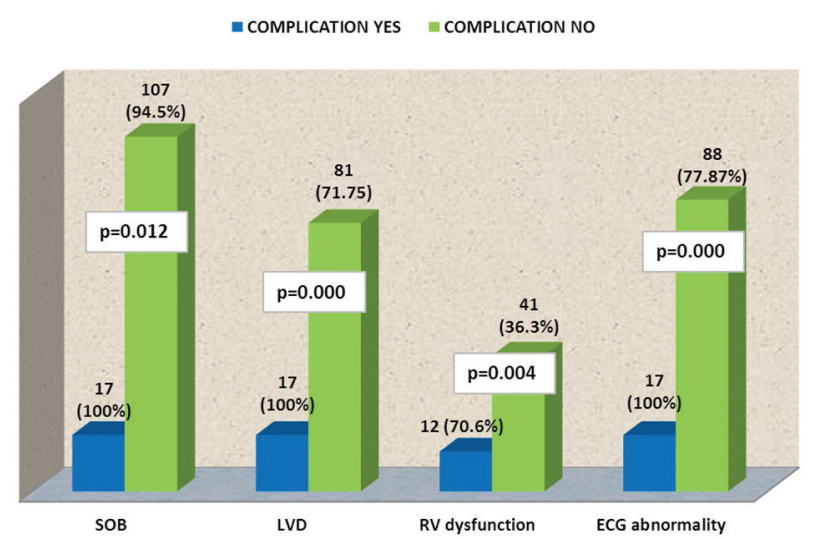

Fig. 2 Bar diagram for comparison of patients with events and without events for shortness of breath, left ventricular dysfunction, right ventricular dysfunction, electrocardiogram abnormality.

\section{Discussion}

Despite the improvement in the treatment strategies in HF, mortality reduction was not to the extent of expectation.
This may be due to the complex syndromic nature of $\mathrm{HF}$, which was understood partially and requires further research to unwind the mysteries of $\mathrm{HF}$ and evolve new therapies for HF management. For this, we require to know about the different prognostic factors for in-hospital outcomes.

In South India also, acute heart failure (AHF) is common, and it is next to the ACS admissions to ICCU. Its prevalence is expected to rise in the near future due to aging and chronicity of ACS. Management of HF with a multiprofessional approach improves outcomes for patients; therefore, adoption of such an approach will go a long way to reduce complications and, hence, stop the rising rate of admission into ICCU and reduce mortality from HF. INDUS study from India, published in 2016, showed the incidence of the HF in the general population was $1.2 / 1000$, and in hospitalized patients, it was $20.4 \%{ }^{3}$ Rheumatic heart disease was the most common cause (52\%) of HF, followed by ischemic heart disease involving the younger age group (39 years). However, in our study, ischemic cardiomyopathy dominated rheumatic HF (39.2 vs. $13.8 \%$ ) with older patients ( 56 years). 
Table 3 Comparison of laboratory parameters in both groups

\begin{tabular}{|l|l|l|l|}
\hline Parameters & Group 1 (without complications) & Group 2 (with complications) & $\boldsymbol{p}$-Value \\
\hline Urea (mg \%) & $45.9 \pm 19.7$ & $57.8 \pm 20.6$ & 0.038 \\
\hline Creatinine (mg \%) & $1.71 \pm 1.89$ & $2.229 \pm 0.992$ & 0.090 \\
\hline $\mathrm{Na}(\mathrm{mEq} / \mathrm{L})$ & $134.06 \pm 7.29$ & $134.06 \pm 7.29$ & 1.000 \\
\hline $\mathrm{K}(\mathrm{mEq} / \mathrm{L})$ & $4.339 \pm 0.391$ & $4.541 \pm 0.332$ & 0.032 \\
\hline Hemoglobin (gm\%) & $11.79 \pm 1.52$ & $11.059 \pm 0.827$ & 0.005 \\
\hline T cell (cell count/in cubic mm) & $12435 \pm 4074$ & $13412 \pm 3083$ & 0.256 \\
\hline Platelets (lakhs) & $1.768 \pm 0.504$ & $1.459 \pm 0.197$ & 0.000 \\
\hline N-terminal pro B-type natriuretic peptide (IU/L) & $15587 \pm 6320$ & $30000 \pm 5222$ & 0.000 \\
\hline
\end{tabular}

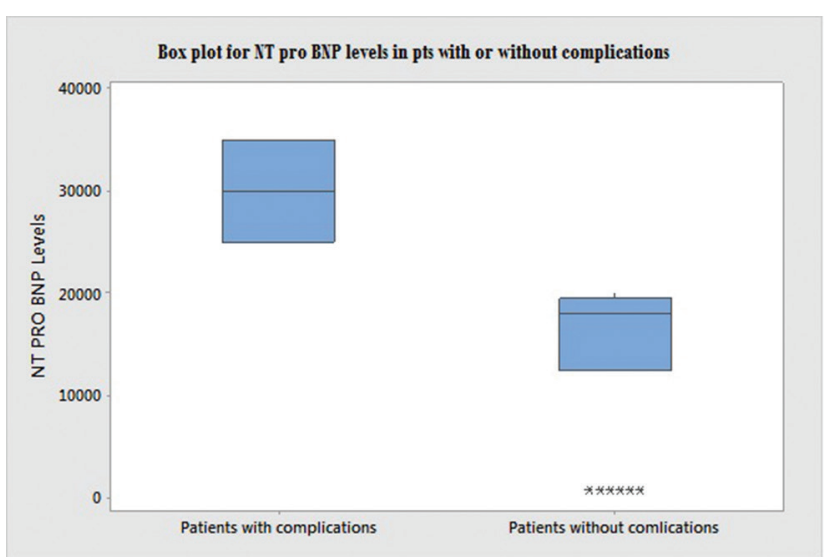

Fig. 3 Box plot for $\mathrm{N}$-terminal pro B-type natriuretic peptide levels in patients with or without events.

Acute Failure Registry (AFAR) study was in 90 acute HF patients with a mean age of 53 years from India showed a mortality rate of $30.8 \%$ in hospital. ${ }^{4}$ In our study, population of AHF also belongs to the same age of 53 years but with better mortality rates $(4.62 \%)$.

Dvornik et al, in 165 patients of acute decompensated heart failure (ADHF), found that died patients were older than survivors. ${ }^{5}$ There was no difference in left ventricular ejection fraction (LVEF) in survivors and dead patients with higher NT pro-BNP levels. In addition, other factors predicting the mortality observed in this study were high high-sensitivity cardiac troponin $\mathrm{T}$, uric acid, urea, creatinine, and red blood cell distribution width (RDW). In the present study, the mortality rate is less than Dvornik et al's study (4.62 vs. $16 \%$ ). This is mainly because of the heterogeneous groups, ranged from HF secondary to ischemic and diabetic cardiomyopathy to cases with chronic rheumatic heart diseases and primary pulmonary PAH in our study. Similar to Dvornik et al's study, we also found that the survivor has less NT proBNP levels. The contrary to this study, our observation was the severity of LV dysfunction with RV dysfunction was an important predictor of mortality. Even though our study does not include RDW estimation, died patients had more anemic than survivors.

Cohen-Solal et al, in their review, mention multiple plasma biomarkers for ADHF other than used for stable chronic HF as prognostic markers. ${ }^{6}$ One of them is ST2 levels. ST2 levels at admission and discharge had an additive prognostic effect on the NT pro-BNP levels. So, also C-reactive protein at admission is associated with in-hospital and long-term mortality. ${ }^{7}$ But in our study, other than NT pro-BNP levels were not studied.

Nakada et al proposed $\mathrm{A}_{2} \mathrm{~B}$ risk score for $\mathrm{ADHF}^{8}$, which included age ( $<65$ years, 0 ; $65-74$ years, $1 ; \geq 75$ years, 2 ), anemia ( $\mathrm{Hb}<10 \mathrm{~g} / \mathrm{dL}, 2 ; 10-11.9 \mathrm{~g} / \mathrm{dL}, 1 ; \geq 12 \mathrm{~g} / \mathrm{dL}, 0)$, and $\operatorname{BNP}(<200 \mathrm{pg} / \mathrm{mL}, 0 ; 200-499 \mathrm{pg} / \mathrm{mL}, 1 ; \geq 500 \mathrm{pg} / \mathrm{mL}, 2)$. Even though we did not calculate this score, our survivors of ADHF were less anemic with less elevation of NT pro-BNP levels than died patients.

Carballo et al's study showed the importance of PAH by ECHO as a bad prognostic marker for outcome in ADHF patients. ${ }^{9}$ In addition, this study mentioned that LVEF and RV function were not the predictors of prognosis. In our study, we have not seen the correlation with the severity of PAH for in-hospital outcomes, but the severity of LV dysfunction and $\mathrm{RV}$ dysfunction on $\mathrm{ECHO}$ were the bad prognostic markers.

The current study is not without limitations, among other things; our study represents the evaluation of a single ICCU and as such may not be generalized to other hospitals in the country.

\section{Conclusion}

Heart failure admissions were increased in the ICU. Out of them, ischemic cardiomyopathy (39.2\%) followed by dilated cardiomyopathy (18.4\%) was the cause of these admissions. Despite the improvement in treatment strategies of ICCU patients in this new era, also the all-cause in-hospital mortality was $4.62 \%$.

\section{Disclosure Statement}

No potential conflict of interest.

\section{References}

1 Benjamin EJ, Muntner P, Alonso A, et al. AHA 2019 Heart Disease and Stroke Statistics. Heart Disease and Stroke Statistics-2019 Update: a report from the American Heart Association. Circulation 2019;139(10):e56-e528

2 Barlera S, Tavazzi L, Franzosi MG, et al. GISSI-HF Investigators. Predictors of mortality in 6975 patients with chronic heart failure in the Gruppo Italiano per lo Studio della 
Streptochinasi nell'Infarto Miocardico-Heart Failure trial: proposal for a nomogram. Circ Heart Fail 2013;6(1):31-39

3 Chaturvedi V, Parakh N, Seth S, et al. Heart failure in India: The INDUS (INDia Ukieri Study) study. J Pract Cardiovasc Sci 2016;2:1-28

4 Seth S, Khanal S, Subramanian S, Krishnan R, Gupta N, Bahl VK. Epidemiology of acute decompensated heart failure in India: the AFAR study (Acute Failure Registry Study). J Pract Cardiovasc Sci 2015;1(1):35-38

5 Dvornik Š, Zaninović Jurjević T, Jurjević N, Lekić A, Zaputović L. Prognostic factors for in-hospital mortality of patients hospitalized for acutely decompensated heart failure. Acta Clin Belg 2018;73(3):199-206

6 Cohen-Solal A, Laribi S, Ishihara S, et al. Prognostic markers of acute decompensated heart failure: the emerging roles of cardiac biomarkers and prognostic scores. Arch Cardiovasc Dis 2015;108(1):64-74

7 Matsumoto H, Kasai T, Sato A, et al. Association between C-reactive protein levels at hospital admission and long-term mortality in patients with acute decompensated heart failure. Heart Vessels 2019;34(12):1961-1968; [Epub ahead of print]

8 Nakada Y, Kawakami R, Matsushima S, et al. Simple risk score to predict survival in acute decompensated heart failure- A2B score. Circ J 2019;83(5):1019-1024

9 Carballo S, Musso P, Garin N, et al. Prognostic value of the echocardiographic probability of pulmonary hypertension in patients with acute decompensated heart failure. J Clin Med 2019;8(10):E1684 